\title{
STUDIES ON BLOOD SUGAR-EFFECT OF BLOOD CONSTITUENTS ON PICRATE SOLUTIONS
}

\author{
A Consideration of thie limitations of the modified \\ LEWIS-BENEDICT TEST *
}

DAVID MURRAY COWIE, M.D., AND JOHN PURL PARSONS, M.D. ANN ARBOR, MICH.

While working on a blood sugar problem we became interested in the statement of McLean ${ }^{1}$ that "it is doubtful whether the picric acid method is at all reliable in the case of whole blood on account of the creatinin (and probably other interfering substances)" which under the conditions of the estimation gives a color similar to that produced by glucose in the presence of picric acid. De Wesselow ${ }^{2}$ claims to show that the Benedict method with whole blood gives 45 per cent. higher readings than the McLean method which utilizes an entirely different principle-precipitation of protein with heat and dialyzed iron and a procedure which is thought to overcome the tendency to oxidation of cuprous oxid during titration.

We have done so much work with the Lewis-Benedict method, and it has been so satisfactory in our hands as a clinical test, that we decided to satisfy ourselves as to the correctness of these statements before giving it up as the routine method in the clinic.

The results of our investigation may be of interest. We have done the following experiments which may have some bearing on the reliability of the Lewis-Benedict test and which may give some added information concerning substances which appear in the blood under abnormal conditions that may influence blood sugar records and explain the occurrence of "hyperglycemia" without glycosuria.

The Effect of Oxalation.-Blood was drawn from four diabetics and one normal person. As quickly as the blood was drawn, 2 c.c. were placed in a volumetric flask, laked with distilled water and precipitated in the ordinary way with picrate solution. The blood was not oxalated. The analysis was carried through immediately. The remainder of the blood was oxalated and determinations were made by the Lewis-Benedict method one half hour later (Table 1).

\footnotetext{
* From the Department of Pediatrics and Infectious Diseases, University of Michigan Hospital.

* Read before the American Pediatric Society, May 30, June 1-2, 1920.

1. Maclean, H.: On the Estimation of Sugar in Blood, Biochem. Jr. $13: 135,1919$.

2. De Wesselow, C. L. V.: Picric Acid Method for Estimation of Sugar in the Blood and Comparison of This Method with that of Maclean, Biochem. Jr. 13: 148, 1919
} 
This shows that oxalation produces no difference in the reaction.

The Effect of Creatinin.-We have shown by a simple gross experiment that creatinin added directly to a 2 c.c. sample of blood increases the blood sugar record given by the Lewis-Benedict method (Table 2).

These amounts of creatinin are many times greater than, probably, ever occur in blood in disease. The highest blood creatinin we find recorded is $33.3 \mathrm{mg}$. per cent. in a case of nephritis due to mercurial. poisoning reported by Meyers and Killian. ${ }^{3}$

We next attempted to determine the lowest limit of sensitivity of the picrate solution to creatinin in water solutions and in blood (Tables 3 and 4).

TABLE 1.--Experiment 1. Nov. 12, 1919

\begin{tabular}{|c|c|c|}
\hline Case & $\begin{array}{c}\text { Nonoxalated } \\
\text { Sample }\end{array}$ & $\begin{array}{c}\text { Oxalated } \\
\text { Sample }\end{array}$ \\
\hline 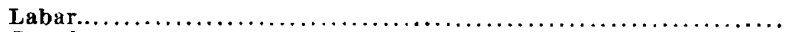 & 0.204 & 0.200 \\
\hline 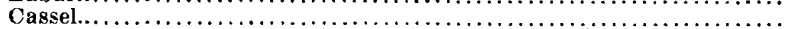 & 0.175 & 0.170 \\
\hline 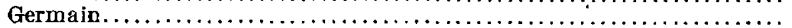 & 0.200 & 0.200 \\
\hline 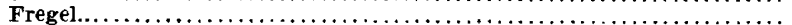 & 0.312 & 0.312 \\
\hline 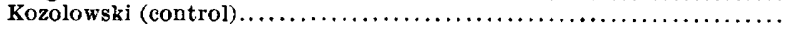 & 0.117 & 0.120 \\
\hline
\end{tabular}

TABLE 2.-EXPeriment 2. Nov. 22, 1919

Control Blood $0.125 \%$ 2.c. Blood $+1 \mathrm{mg}$. Creatinin $=$ $50 \mathrm{mg}$. per 100 $0.180 \%$
2 c.c. Blood $+2 \mathrm{mg}$. Creatinin $=$ $100 \mathrm{mg}$. per 100 $0.260 \%$

In Series 2 of this experiment a distinct color change with a 2 c.c. sample of a creatinin solution containing $2.5 \mathrm{mg}$. in $100 \mathrm{c.c}$. of water is shown. In other words, the picrate solution is sensitive to 0.00005 gm. creatinin in water.

A distinct color change occurs in the picrate solution when 2 c.c. of a solution of 6 or $7 \mathrm{mg}$. of creatinin to 100 c.c. of water are added to a 2 c.c. sample of normal blood (Table 5). In other words, in order that creatinin in the blood may have any influence on a LewisBenedict blood sugar record, it must be increased at least 6 or $7 \mathrm{mg}$. above normal which would give a creatinin value of $9 \mathrm{mg}$. per cent. or above.

The remarkable sensitiveness of the picrate solution is better comprehended when we recognize the fact that in the 2 c.c. sample of blood, plus the creatinin solution, there is only $0.00016 \mathrm{gm}$. of creatinin present.

3. Meyers, V. C., and Killian, J. A.: Prognostic Value of Creatinin of the Blood in Nephritis, Am. J. M. Sc. 157:674, 1919. 
We have seen that the highest blood creatinin is $33.3 \mathrm{mg}$. per cent. $^{3}$ If the record obtained by this amount (0.045, Table 5) added to blood is added to a normal blood sugar record, $0.150+0.45=0.195$, the upper border of normal is certainly reached. If, on the other hand, a case of diabetes was complicated by a marked renal disturbance inducing a high blood creatinin, one might expect a considerable increase in the blood sugar record not due to glucose.

TABle 3.-Experiment 3. Dec. 29. 1919. Creatinin in Water. Series 1

\begin{tabular}{|c|c|c|c|}
\hline \multirow{2}{*}{$\begin{array}{l}\text { Size } \\
\text { of Water } \\
\text { Sample }\end{array}$} & \multicolumn{2}{|r|}{ Creatinin } & \multirow{2}{*}{$\begin{array}{c}\text { Blood Sugar } \\
\text { Record, } \\
\text { L.-B. Test }\end{array}$} \\
\hline & Amount Added & Strength of Solution & \\
\hline $\begin{array}{l}2 \text { c.c. control } \\
2 \text { c.c. } \\
2 \text { c.c. } \\
2 \text { c.c. } \\
2 \text { c.c. } \\
2 \text { c.c. } \\
2 \text { c.e. } \\
2 \text { c.c. } \\
2 \text { c.c. } \\
2 \text { c.c. } \\
2 \text { c.c. } \\
2 \text { c.c. } \\
2 \text { c.c. } \\
2 \text { c.e. } \\
2 \text { c.c. } \\
2 \text { c.c. } \\
2 \text { c.c. } \\
2 \text { c.c. } \\
2 \text { c.c. } \\
2 \text { c.c. } \\
2 \text { c.c. } \\
2 \text { c.c. control }\end{array}$ & $\begin{array}{l}2 \text { c.c. } \\
2 \text { c.e. } \\
2 \text { c.c. } \\
2 \text { c.c. } \\
2 \text { c.c. } \\
2 \text { c.c. } \\
2 \text { c.e. } \\
2 \text { c.c. } \\
2 \text { c.c. } \\
2 \text { c.c. } \\
2 \text { c.c. } \\
2 \text { c.c. } \\
2 \text { c.c. } \\
2 \text { c.c. } \\
2 \text { c.c. } \\
2 \text { c.c. } \\
2 \text { c.c. } \\
2 \text { c.c. } \\
2 \text { c.c. } \\
2 \text { c.c. } \\
\text { …. }\end{array}$ & 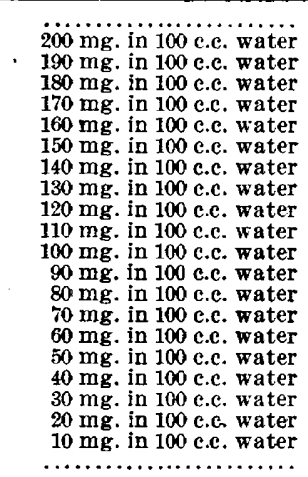 & $\begin{array}{l}0.040 \\
0.333 \\
0.285 \\
0.270 \\
0.270 \\
0.270 \\
0.250 \\
0.250 \\
0.222 \\
0.225 \\
0.222 \\
0.222 \\
0.215 \\
0.220 \\
0.220 \\
0.182 \\
0.166 \\
0.143 \\
0.135 \\
0.090 \\
0.090 \\
0.040\end{array}$ \\
\hline
\end{tabular}

TABle 4.--Experiment 3. Dec. 29, 1919. Creatinin in Water. Series 2

\begin{tabular}{|c|c|c|c|}
\hline \multirow{2}{*}{$\begin{array}{c}\text { Size } \\
\text { of Water } \\
\text { Sample }\end{array}$} & \multicolumn{2}{|c|}{ Creatinin } & \multirow{2}{*}{$\begin{array}{c}\text { Blood Sugar } \\
\text { Record, } \\
\text { L.-B. Test }\end{array}$} \\
\hline & Amount Added & Strength of Solution & \\
\hline $\begin{array}{l}2 \text { c.c. control } \\
2 \text { c.c. } \\
2 \text { c.c. } \\
2 \text { c.c. } \\
2 \text { c.c. } \\
2 \text { c.c. } \\
2 \text { c.c. } \\
2 \text { c.c. } \\
2 \text { c.c. } \\
2 \text { c.c. control }\end{array}$ & $\begin{array}{l}2 \text { c.c. } \\
2 \text { c.c. } \\
2 \text { c.c. } \\
2 \text { c.c. } \\
2 \text { c.c. } \\
2 \text { c.c. } \\
2 \text { c.c. } \\
2 \text { c.c. } \\
\cdots\end{array}$ & $\begin{array}{r}60 \mathrm{mg} \text {. in } 100 \text { c.c. water } \\
50 \mathrm{mg} \text {. in } 100 \text { c.c. water } \\
40 \mathrm{mg} \text {. in } 100 \text { c.c. water } \\
30 \mathrm{mg} \text {. in } 100 \text { c.c. water } \\
20 \mathrm{mg} \text {. in } 100 \text { c.c. water } \\
10 \mathrm{mg} \text {. in } 100 \text { c.c. water } \\
5 \mathrm{mg} \text {. in } 100 \text { c.c. water } \\
21 / 2 \mathrm{mg} \text {. In } 100 \text { c.c. water } \\
\ldots \ldots \ldots \ldots \ldots \ldots \ldots \ldots\end{array}$ & $\begin{array}{l}0.040 \\
0.200 \\
0.160 \\
0.133 \\
0.111 \\
0.080 \\
0.070 \\
0.060 \\
0.050 \\
0.040\end{array}$ \\
\hline
\end{tabular}

The Effect of Urea.-If 4 or $5 \mathrm{mg}$. urea crystals are added to a 2 c.c. sample of blood, a color change in the picrate solution may be obtained. This amount is far above the amount that ever occurs in the circulating blood. With graded and accurately measured amounts of urea, such as might occur as excess in circulating blood, no change in color whatsoever takes place (Tables 6 and 7).

Dilutions of urea in blood exactly like those tabulated for water were set up and run. There was absolutely no change produced by these amounts of urea. 
TABle 5.-Experiment 4. Jan. 2, 1920 . Creatinin in Blood. Series 1

\begin{tabular}{|c|c|c|c|c|}
\hline \multirow{2}{*}{$\begin{array}{c}\text { Size } \\
\text { of } \\
\text { Blood } \\
\text { Sample }\end{array}$} & \multicolumn{2}{|r|}{ Creatinin } & \multirow{2}{*}{$\begin{array}{c}\text { Blood } \\
\text { Sugar } \\
\text { Record, } \\
\text { L.-B. Test }\end{array}$} & \multirow{2}{*}{$\begin{array}{c}\text { Difference } \\
\text { from } \\
\text { Control } \\
\text { Average }\end{array}$} \\
\hline & $\begin{array}{l}\text { Amount } \\
\text { Added }\end{array}$ & $\begin{array}{l}\text { Strength of } \\
\text { Solution }\end{array}$ & & \\
\hline $\begin{array}{l}2 \text { c.c.* } \\
2 \text { c.e. } \\
2 \text { c.c. } \\
2 \text { c.c. } \\
2 \text { c.c. } \\
2 \text { c.c. } \\
2 \text { c.c. } \\
2 \text { c.c. } \\
2 \text { c.c. } \\
2 \text { c.c. } \\
2 \text { c.c. } \\
2 \text { c.c. } \\
2 \text { c.c. } \\
2 \text { c.c. } \\
2 \text { c.e. } \\
2 \text { c.c. } \\
2 \text { c.c. } \\
2 \text { c.c. } \\
2 \text { c.c. } \\
2 \text { c.c. } \\
2 \text { c.c.* }\end{array}$ & $\begin{array}{l}2 \text { e.c. } \\
2 \text { c.c. } \\
2 \text { c.c. } \\
2 \text { c.c. } \\
2 \text { c.c. } \\
2 \text { c.c. } \\
2 \text { c.e. } \\
2 \text { c.e. } \\
2 \text { c.e. } \\
2 \text { c.c. } \\
2 \text { c.c. } \\
2 \text { c.c. } \\
2 \text { c.e. } \\
2 \text { c.e. } \\
2 \text { c.c. } \\
2 \text { e.c. } \\
2 \text { c.e. } \\
2 \text { e.e. } \\
2 \text { c.e. } \\
\text { …. }\end{array}$ & 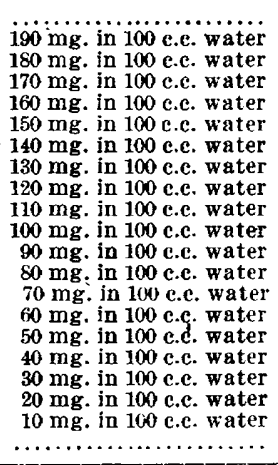 & $\begin{array}{l}0.118 \\
0.475 \\
0.330 \\
0.330 \\
0.320 \\
0.350 \\
0.222 \\
0.222 \\
0.224 \\
0.208 \\
0.247 \\
0.247 \\
0.243 \\
0.218 \\
0.221 \\
0.198 \\
0.165 \\
0.164 \\
0.140 \\
0.132 \\
0.120\end{array}$ & $\begin{array}{l}0.356 \\
0.211 \\
0.221 \\
0.201 \\
0.131 \\
0.103 \\
0.103 \\
0.105 \\
0.189 \\
0.128 \\
0.128 \\
0.124 \\
0.099 \\
0.102 \\
0.079 \\
0.046 \\
0.045 \\
0.021 \\
0.013\end{array}$ \\
\hline $\begin{array}{c}\text { Series } 2 \\
2 \text { c.c.* } \\
2 \text { c.e. } \\
2 \text { c.e. } \\
2 \text { c.c. } \\
2 \text { c.c. } \\
2 \text { c.c. } \\
2 \text { c.c. } \\
2 \text { c.c. } \\
2 \text { c.c. } \\
2 \text { c.e. } \\
2 \text { c.c. } \\
2 \text { c.c.* }\end{array}$ & $\begin{array}{l}2 \text { c.c. } \\
2 \text { c.e. } \\
2 \text { c.c. } \\
2 \text { c.c. } \\
2 \text { c.e. } \\
2 \text { c.e. } \\
2 \text { c.c. } \\
2 \text { c.c. } \\
2 \text { c.e. } \\
2 \text { c.c. } \\
\cdots\end{array}$ & 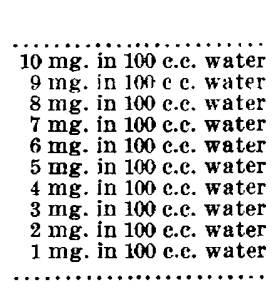 & $\begin{array}{l}0.110 \\
0.141 \\
01143 \\
0.127 \\
0.122 \\
0.118 \\
0.117 \\
0.117 \\
0.118 \\
0.111 \\
0.108 \\
0.113\end{array}$ & $\begin{array}{l}0.030 \\
0.033 \\
0.016 \\
0.011 \\
0.007 \\
0.006 \\
0.006 \\
0.007\end{array}$ \\
\hline
\end{tabular}

* Control.

TABLE 6.-Experiment 5. May 20, 1920. URea in Water

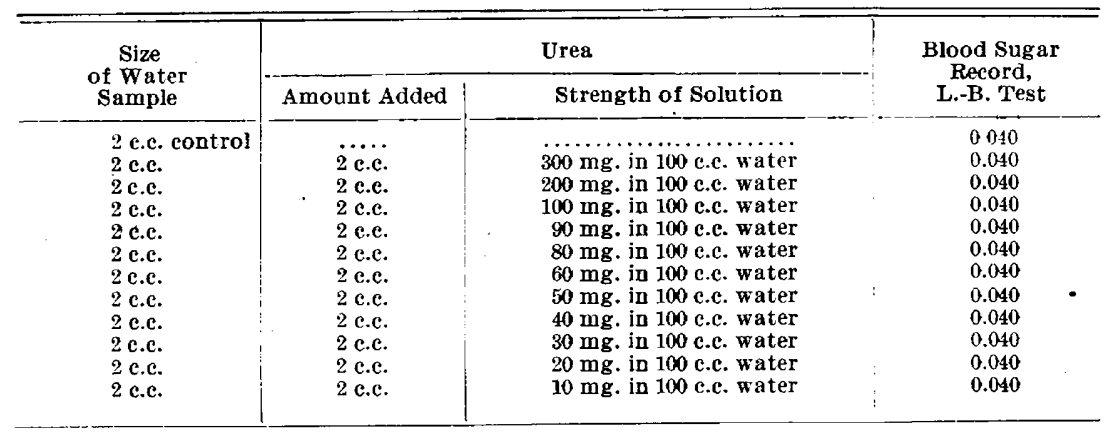

TABLE 7.-Experiment 6, May 20, 1920 . Urea in Blood

\begin{tabular}{|c|c|c|c|}
\hline $\begin{array}{c}\text { Size of } \\
\text { Blood Sample }\end{array}$ & Amount Added & -Urea- $\quad$ Strength of Solution & $\begin{array}{c}\text { Blood Sugar Record, } \\
\text { L.-B. Test }\end{array}$ \\
\hline $\begin{array}{l}2 \text { c.c. control } \\
2 \text { c.e. }\end{array}$ & $\ddot{2 c . c .}$ & $300 \mathrm{mg}$. in 100 c.c. water & $\begin{array}{l}0.112 \\
0.113\end{array}$ \\
\hline
\end{tabular}


From the above experiment it will be seen that in these amounts urea does not interfere.

Uric acid does not interfere. Ammonia nitrogen does not interfere.

The Effect of the Amino Acids.-Glycocol: Two c.c. of water plus a knife point of glycocol. Boiling for ten minutes produces no change. On standing twenty minutes no change. After complete cooling one hour and fifteen minutes, consolidation in both tubes, the glycocol tube shows a definite change. After reheating for ten minutes the readings shown in Table 9 were obtained:

TABLE 8.-Experiment 7. May 22, 1920. The Effect of Uric Acid

\begin{tabular}{|c|c|}
\hline 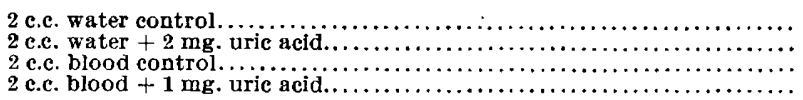 & $\begin{array}{l}0.040 \\
0.040 \\
0.100 \\
0.100\end{array}$ \\
\hline
\end{tabular}

TABLE 9.-Experiment 8. EFfect OF Glycocol

\begin{tabular}{|c|c|}
\hline 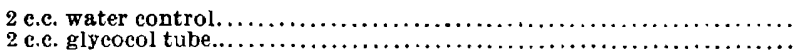 & $\begin{array}{l}0.040 \\
0.190\end{array}$ \\
\hline
\end{tabular}

TABLE 10.-Experiment 9. Epinephrin in Water

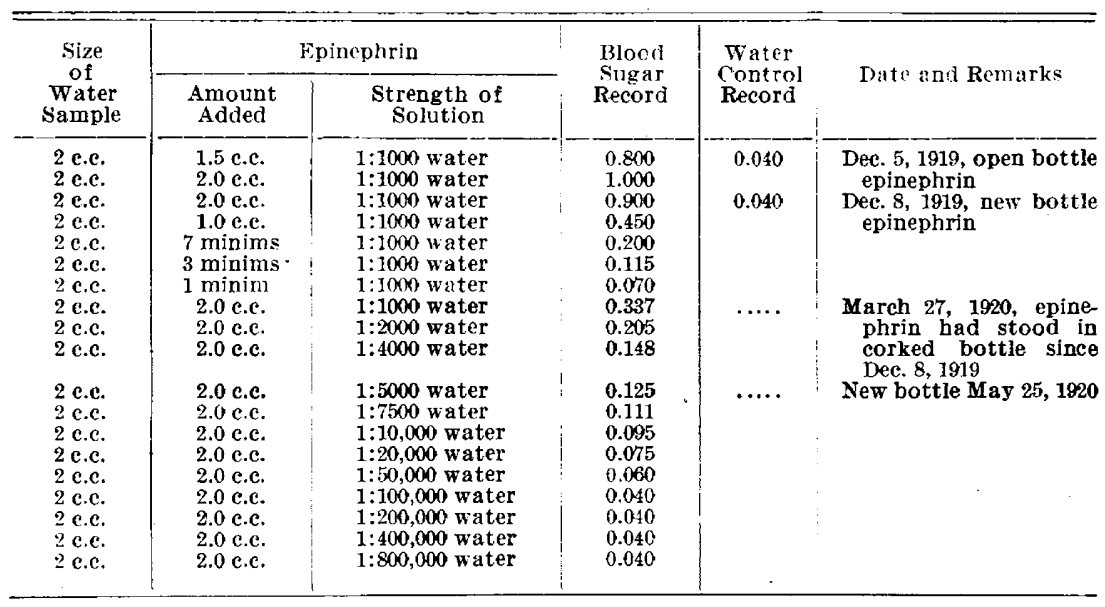

Tyrosin, taurin, tryptophan and alanin induce no change. These are all the amino acids we could find.

The Effect of Epinephrin.-If a drop or two of epinephrrin solution $(1: 1,000)$ is added to picrate, Fehling's or Benedict's solution, a distinct reduction takes place. The experiments tabulated in Table 10 show the lowest limit of sensitivity of the picrate solution to epinephrin in water and in blood. 
The lowest limit of sensitivity in water is 2 c.c. of a $1: 50,000$ solution, or $0.00004 \mathrm{gm}$. The difference in the records obtained with the same dilution is explained by the condition of the sample, age, etc.

The experiment tabulated in Table 11 shows that epinephrin in infinitesimally small amounts induces a color change when added to blood. The lowest limit of sensitivity of the picrate solution of the Lewis-Benedict test to epinephrin added to blood is safely placed at 0.000025 per cent., or in other words, $0.025 \mathrm{mg}$. per cent. If we calculate the amount present in a 2 c.c. sample of blood plus 2 c.c. of a $1: 4,000,000$ solution, the picrate solution reacts to $0.0000005 \mathrm{gm}$. of epinephrin (adrenalin). From this it will be seen that the picrate solution is many-fold more sensitive to solutions of epinephrin added to blood than to water.

TABLE 11.-Experiment 10. April 30, 1920. Epinephrin in Blood

\begin{tabular}{|c|c|c|c|}
\hline \multirow{2}{*}{$\begin{array}{c}\text { Size } \\
\text { of Water } \\
\text { Sample }\end{array}$} & \multicolumn{2}{|r|}{ Fpinephrin } & \multirow{2}{*}{$\begin{array}{l}\text { Blood Sugar } \\
\text { Record, } \\
\text { L.-B. Test }\end{array}$} \\
\hline & Amount Added & Strength of Solution & \\
\hline $\begin{array}{l}2 \text { c.c. control } \\
2 \text { c.c. control } \\
2 \text { c.c. } \\
2 \text { c.c. } \\
2 \text { c.c. } \\
2 \text { c.c. } \\
2 \text { c.c. } \\
2 \text { c.c. } \\
2 \text { c.c. } \\
2 \text { c.c. } \\
2 \text { c.c. } \\
2 \text { c.c. } \\
2 \text { c.c. } \\
2 \text { c.c. } \\
2 \text { c.c. conrtol }\end{array}$ & $\begin{array}{l}\cdots \\
2 \cdots . . \\
2 \text { c.c. } \\
2 \text { c.e. } \\
2 \text { c.c. } \\
2 \text { c.c. } \\
2 \text { c.c. } \\
2 \text { c.c. } \\
2 \text { c.c. } \\
2 \text { c.c. } \\
2 \text { c.c. } \\
2 \text { c.c. } \\
2 \text { c.c. } \\
2 \text { c.c. } \\
\cdots \cdots\end{array}$ & $\begin{array}{l}\ldots \ldots \ldots \ldots \ldots \ldots \ldots \ldots \\
1 \text { mg. in } 100,000 \text { c.c. water } \\
1 \mathrm{mg} \text {. in } 200,000 \text { c.c. water } \\
1 \mathrm{mg} \text {. in } 400,000 \text { c.c. water } \\
1 \mathrm{mg} \text {. in } 500,000 \text { c.c. water } \\
1 \mathrm{mg} \text {. in } 1,000,000 \text { c.c. water } \\
1 \mathrm{mg} \text {. in } 1,500,000 \text { c.c. water } \\
1 \mathrm{mg} \text {. in } 2,000,000 \text { c.c. water } \\
1 \mathrm{mg} \text {. in } 2,500,000 \text { c.c. water } \\
1 \mathrm{mg} \text {. in } 3,000,000 \text { c.c. water } \\
1 \mathrm{mg} \text {. in } 4,000,000 \text { c.c. water } \\
1 \mathrm{mg} \text {. in } 2,000,000 \text { c.c. water } \\
1 \mathrm{mg} \text {. in } 1.000,000 \text { c.c. water } \\
\ldots \ldots \ldots \ldots \ldots \ldots \ldots \ldots\end{array}$ & $\begin{array}{l}0.127 \\
0.120 \\
0.196 \\
0.171 \\
0.165 \\
0.153 \\
0.140 \\
0.138 \\
0.136 \\
0.135 \\
0.133 \\
0.130 \\
0.160 \\
0.176 \\
0.114\end{array}$ \\
\hline
\end{tabular}

THE ACETONE BODIES

The Effect of Acetone.-Unless added in very large amounts, acetone in water solution produces no effect on picrate solutions. The acetone blows off. If acetone is added after heating the picrate and carbonate mixture a color change occurs with smaller amounts.

The experiments summarized in Table 15 show the sensitiveness of the picrate solution to solutions of acetone added to the blood.

It will be observed that a distinct color change occurs in the picrate solution when a concentration of 2 c.c. of a solution of $0.05 \mathrm{mg}$. of acetone in 100 c.c. of water is added to 2 c.c. of normal blood. Placing the normal acetone content of the blood at 1 or $2 \mathrm{mg}$. per liter, ${ }^{4}$ or

4. "Normal blood when analyzed as described for total acetone bodies yields only 1 or $2 \mathrm{mg}$. of precipitate, equivalent to from 0.013 to $0.026 \mathrm{gm}$. of acetone per liter. In diabetes as much as $2.5 \mathrm{gm}$. (250 mg.) of acetone bodies, calculated as acetone, has been observed, while patients under ordinarily good control show from 0.1 to $0.4 \mathrm{gm} . "$ (per liter). 
TABLE 12.-Experiment 11. Dec. 8, 1919. The Effect of Pituitary Extract

\begin{tabular}{|c|c|}
\hline 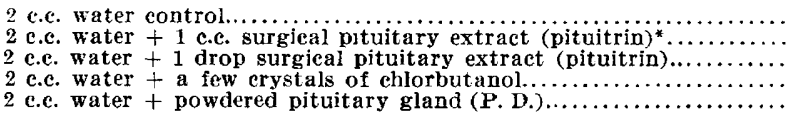 & $\begin{array}{l}0.040 \\
0.115 \\
0.040 \\
0.342 \\
0.040\end{array}$ \\
\hline
\end{tabular}

* Surgical pituitary extract (pituitrin) is put up in chlorbutanol.

Pituitary extract induced no change.

TABle 13.-Experiment 12. Thyroid Extract in Water

\begin{tabular}{|c|c|}
\hline 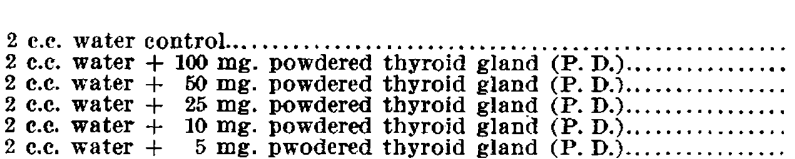 & $\begin{array}{l}\text { Gm.,Per Cent. } \\
0.040 \\
0.100 \\
\mathbf{0 . 0 8 0} \\
0.060 \\
\mathbf{0 . 0 4 0} \\
\mathbf{0 . 0 4 0}\end{array}$ \\
\hline
\end{tabular}

TABLE 14.--Experiment 12. Thyroid Extract in Blood

\begin{tabular}{|c|c|}
\hline 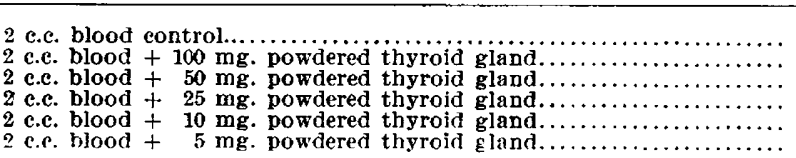 & $\begin{array}{c}\text { Gm., Per Oent. } \\
0.125 \\
0.200 \\
0.190 \\
0.166 \\
0.140 \\
0.130\end{array}$ \\
\hline
\end{tabular}

Thyroid extract when added to blood induces a change.

TABLE 15.-Experiment 13. ACETONe in Blood

\begin{tabular}{|c|c|c|c|c|c|c|}
\hline \multirow{2}{*}{$\begin{array}{c}\text { Size } \\
\text { of } \\
\text { Blood } \\
\text { Sample }\end{array}$} & \multicolumn{2}{|r|}{ Acetone } & \multicolumn{4}{|c|}{ Blood Sugar Record, L.-B. Test } \\
\hline & $\begin{array}{l}\text { Amount } \\
\text { Added }\end{array}$ & $\begin{array}{l}\text { Strength of } \\
\text { Solution }\end{array}$ & $\begin{array}{l}\text { Series } 1 \\
\text { May } 1\end{array}$ & $\begin{array}{l}\text { Series } 2 \\
\text { May } 3\end{array}$ & $\begin{array}{l}\text { Series } 3 \\
\text { May } 4\end{array}$ & $\begin{array}{l}\text { Series } 4 \\
\text { May } 13\end{array}$ \\
\hline $\begin{array}{l}\text { Control } \\
2 \text { c.e. } \\
2 \text { c.c. } \\
2 \text { c.c. } \\
2 \text { c.c. } \\
2 \text { c.e. } \\
2 \text { e.c. } \\
2 \text { e.c. } \\
2 \text { c.c. } \\
2 \text { c.c. } \\
2 \text { c.e. } \\
2 \text { c.c. } \\
2 \text { c.c. } \\
2 \text { c.c. } \\
2 \text { c.c. } \\
2 \text { c.c. }\end{array}$ & $\begin{array}{l}2 \text { c.e. } \\
2 \text { c.e. } \\
2 \text { c.e. } \\
2 \text { c.e. } \\
2 \text { c.c. } \\
2 \text { c.c. } \\
2 \text { c.e. } \\
2 \text { c.e. } \\
2 \text { c.e. } \\
2 \text { c.c. } \\
2 \text { c.e. } \\
2 \text { c.e. } \\
2 \text { c.c. } \\
2 \text { c.c. } \\
2 \text { c.c. }\end{array}$ & $\begin{array}{r}\text { *20 mg. to } 100 \text { c.e. water } \\
10 \mathrm{mg} \text {. to } 100 \text { c.c. water } \\
9 \mathrm{mg} \text {. to } 100 \text { c.c. water } \\
7 \mathrm{mg} \text {. to } 100 \text { c.c. water } \\
5 \mathrm{mg} \text {. to } 100 \text { c.c. water } \\
4 \mathrm{mg} \text {. to } 100 \text { c.c. wtaer } \\
3 \mathrm{mg} \text {. to } 100 \text { c.c. water } \\
2 \mathrm{mg} \text { to } 100 \text { c.c. water } \\
1 \mathrm{mg} \text {. to } 100 \text { c.c. wtaer } \\
0.75 \mathrm{mg} \text {. to } 100 \text { c.c. water } \\
0.50 \mathrm{mg} \text {. to } 100 \text { c.c. water } \\
0.25 \mathrm{mg} \text {. to } 100 \text { c.c. water } \\
0.20 \mathrm{mg} \text {. to } 100 \text { c.c. water } \\
0.10 \mathrm{mg} \text { to } 100 \text { c.c. water } \\
0.05 \mathrm{mg} \text {. to } 100 \text { c.e. water }\end{array}$ & $\begin{array}{l}0.113 \dagger \\
0.250 \\
0.230 \\
0.230 \\
0.198 \\
0.185 \\
0.185 \\
0.180 \\
0.170 \\
0.150 \\
\ldots \ldots \\
\ldots \ldots \\
\ldots \ldots \\
\ldots \ldots \\
\ldots . \\
\ldots . .\end{array}$ & $\begin{array}{l}0.117 \ddagger \\
0.210 \\
0.195 \\
\\
0.180 \\
\ldots \ldots \\
\ldots .155 \\
\ldots \ldots \\
0.140 \\
0.135 \\
0.125 \\
\ldots \ldots \\
\cdots \cdots \\
\ldots \ldots\end{array}$ & $\begin{array}{l}\ldots \ldots \\
\ldots \ldots \\
\ldots \ldots \\
\ldots .14 \\
0.144 \\
0.143 \\
0.128 \\
0.127 \\
0.121 \\
0.114\end{array}$ & $\begin{array}{l}0.190 \\
0.187 \\
0.193 \\
0.189 \\
\\
0.172 \\
0.170 \\
\\
0.144 \\
0.140\end{array}$ \\
\hline
\end{tabular}

* Acetone C. P. dilutions based on specific gravity 0.797 . Samples run with $100,75,50,25$, 15 and $10 \mathrm{mg}$. to 100 c.c. of water were practically black; no attempt was made to read them. + Blood from a convalescent variola patient.

t Blood from a convalescent variola patient.

$\$$ Blood from a normal person.

ๆ The blood was taken from a boy who had an afebrile pyelitis. 
from 0.001 to $0.002 \mathrm{mg}$. per cent., we are safe in saying that acetone interferes in the Lewis-Benedict test when the acetone content of the blood is increased $0.05 \mathrm{mg}$. per cent. above normal.

The remarkable sensitiveness of the picrate solution to acetone is better comprehended when we recognize the fact that in a 2 c.c. sample of blood to which is added 2 c.c. of a solution of $0.05 \mathrm{mg}$. of acetone to 100 c.c. of water, there is only $0.021 \mathrm{mg}$. $(0.0000021 \mathrm{gm}$.) present.

TABle 16.-Showing the Comparative Sensitiveness of the Lewis-Benfoict Test to Solutions of Glucose in Blood and Acetone in Blood

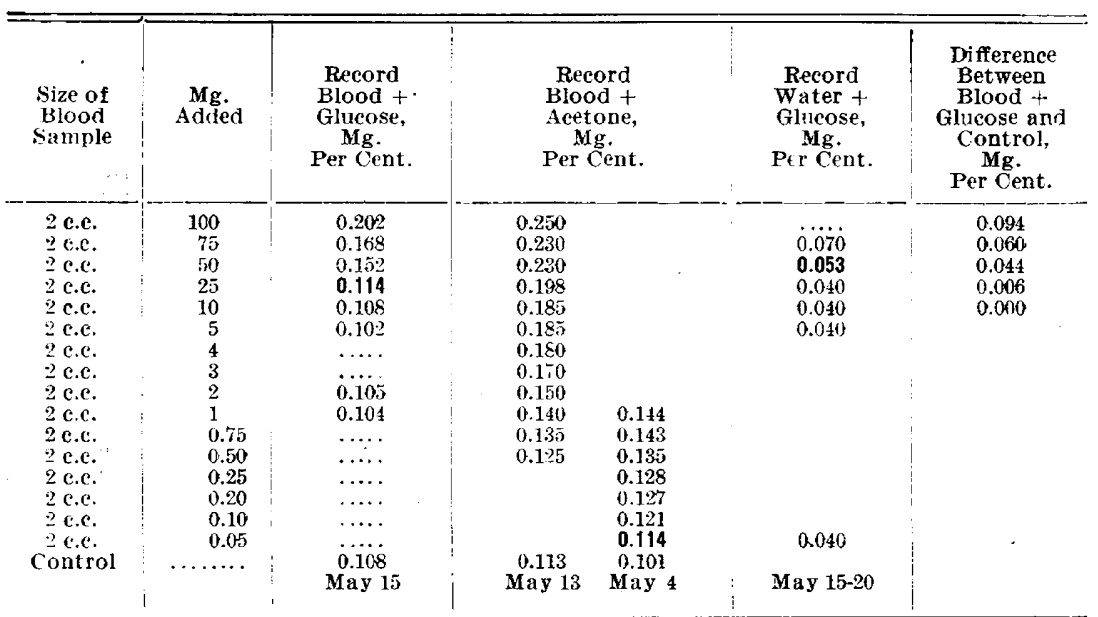

Heavy figures show limit of sensitiveness.

TABLE 17.-Experiment 14. May 15, 1920. Glucose in Water

\begin{tabular}{|c|c|}
\hline 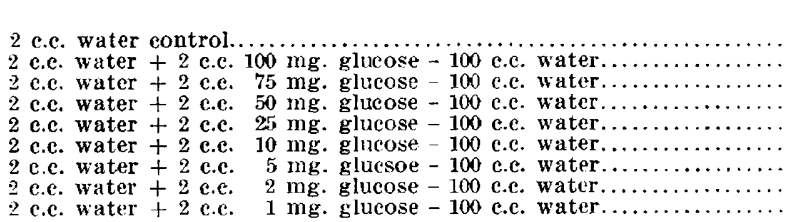 & $\begin{array}{l}\text { Gm. Per Cent. } \\
0.040 \\
\text { Lost } \\
0.070 \\
0.053 \\
0.040 \\
0.040 \\
0.040 \\
0.040 \\
0.040\end{array}$ \\
\hline
\end{tabular}

It may be of interest to show the comparative sensitiveness of picrate solution to solutions of glucose and solutions of acetone. Table 16 is compiled from previous experiments.

The picrate solution is sensitive to glucose in a concentration of $25 \mathrm{mg}$. per cent., to acetone in a concentration of $0.05 \mathrm{mg}$. per cent. Glucose water solutions give distinct color change at $50 \mathrm{mg}$. per cent. (Table 17).

The picrate solution used in the Lewis-Benedict blood sugar method is 500 times more sensitive to acetone than it is to glucose. 
TABLE 18.-Experiment 15. May 21, 1920. Diacetic Acid in Blood

\begin{tabular}{|c|c|c|c|}
\hline \multirow{2}{*}{$\begin{array}{c}\text { Size of } \\
\text { Blood Sample }\end{array}$} & \multicolumn{2}{|r|}{ Diacetic Acia } & \multirow{2}{*}{$\begin{array}{c}\text { Blood } \\
\text { Sugar } \\
\text { Record, } \\
\text { L.-B. Test }\end{array}$} \\
\hline & $\begin{array}{c}\text { Amount } \\
\text { Added, } \mathbf{M g} \text {. }\end{array}$ & $\begin{array}{l}\text { Strength of } \\
\text { Solution }\end{array}$ & \\
\hline $\begin{array}{l}2 \text { c.c. control } \\
2 \text { c.c. } \\
2 \text { c.c. } \\
2 \text { c.c. } \\
2 \text { c.c. } \\
2 \text { c.c. } \\
2 \text { c.c. } \\
2 \text { c.c. } \\
2 \text { c.c. } \\
2 \text { c.c. } \\
2 \text { c.c. } \\
2 \text { c.c. } \\
2 \text { e.e. } \\
2 \text { c.c. } \\
2 \text { c.c. } \\
2 \text { c.c. } \\
2 \text { c.c. }\end{array}$ & $\begin{array}{c}100 \\
80 \\
60 \\
50 \\
40 \\
30 \\
20 \\
10 \\
5 \\
5 \\
0.75 * \\
0.50 \\
0.25 \\
0.10 \\
0.05 \\
0.025\end{array}$ & $\begin{array}{l}\text { Acetic-acto-ester in } 100 \text { c.c. water } \\
\text { Acetic-aceto-ester in } 100 \text { c.c. water } \\
\text { Acetic-aceto-ester in } 100 \text { c.c. water } \\
\text { Acetic-aceto-ester in } 100 \text { c.c. water } \\
\text { Acetic-aceto-ester in } 100 \text { c.c. water } \\
\text { Acetic-aceto-ester in } 100 \text { c.c. water } \\
\text { Acetic-aceto-ester in } 100 \text { c.c. water } \\
\text { Acetic-aceto-ester in } 100 \text { c.c. water } \\
\text { Acetic-aceto-ester in } 100 \text { c.c. water } \\
\text { Acetic-aceto-ester in } 100 \text { c.c. water } \\
\text { Acetic-aceto-ester lu } 100 \text { c.c. water } \\
\text { Acetic-aceto-ester in } 100 \text { c.c. water } \\
\text { Acetic-aceto-ester in } 100 \text { c.c. water } \\
\text { Acetic-acteo-ester in } 100 \text { c.c. water } \\
\text { Acetic-aceto-ester in } 100 \text { c.c. water } \\
\text { Acetic-aceto-ester in } 100 \text { c.c. water }\end{array}$ & $\begin{array}{l}0.113 \\
0.256 \\
0.243 \\
0.251 \\
0.218 \\
0.210 \\
0.201 \\
0.195 \\
0.164 \\
0.147 \\
0.144 \\
0.128 \\
0.127 \\
0.115 \\
0.115 \\
0.113 \\
0.112\end{array}$ \\
\hline
\end{tabular}

* From this point on a different sample of blood was used. The record of the control reading was inadvertently omitted from the permanent record book. It was practically the same as the first control.

TABle 19.-Experiment 15. Diacetic Acid in Water

\begin{tabular}{|c|c|c|c|}
\hline \multirow{2}{*}{$\begin{array}{c}\text { Size of } \\
\text { Blood Sample }\end{array}$} & \multicolumn{2}{|r|}{ Diacetic Acid } & \multirow{2}{*}{$\begin{array}{c}\text { Blood } \\
\text { Sugar } \\
\text { Record, } \\
\text { L.-B. Test }\end{array}$} \\
\hline & $\begin{array}{l}\text { Amount } \\
\text { Added, } \mathbf{M g} \text {. }\end{array}$ & $\begin{array}{l}\text { Strength of } \\
\text { Solution }\end{array}$ & \\
\hline $\begin{array}{l}2 \text { c.c. control } \\
2 \text { c.c. } \\
2 \text { c.c. } \\
2 \text { c.c. } \\
2 \text { c.e. } \\
2 \text { c.c. } \\
2 \text { c.e. } \\
2 \text { c.c. } \\
2 \text { c.c. } \\
2 \text { c.c. } \\
2 \text { c.c. } \\
2 \text { c.c. } \\
2 \text { c.c. }\end{array}$ & $\begin{array}{r}100 \\
80 \\
60 \\
50 \\
40 \\
30 \\
20 \\
10 \\
5 \\
4 \\
2 \\
1\end{array}$ & $\begin{array}{l}\text { Aceto-acetic-ester in } 100 \text { c.c. water } \\
\text { Aceto-acetic-ester in } 100 \text { c.c. water } \\
\text { Aceto-acetic-ester in } 100 \text { c.c. water } \\
\text { Aceto-acetic-ester in } 100 \text { c.c. water } \\
\text { Aceto-acetic-ester in } 100 \text { c.c. water } \\
\text { Aceto-acetic-ester in } 100 \text { c.c. water } \\
\text { Aceto-acetic-ester in } 100 \text { c.c. water } \\
\text { Aceto-acetic-ester in } 100 \text { c.c. water } \\
\text { Aceto-acetic-ester in } 100 \text { c.c. water } \\
\text { Aceto-acetic-ester in } 100 \text { c.c. water } \\
\text { Aceto-acetic-ester in } 100 \text { c.c. water } \\
\text { Aceto-acetic-ester in } 100 \text { c.c. water }\end{array}$ & $\begin{array}{l}0.040 \\
0.391 \\
0.256 \\
0.232 \\
0.198 \\
0.165 \\
0.143 \\
0.128 \\
0.115 \\
0.095 \\
0.083 \\
0.071 \\
0.049\end{array}$ \\
\hline
\end{tabular}

TABLE 20.-The Limit of Sensitivity of Picrate Solution

\begin{tabular}{|c|c|c|c|}
\hline 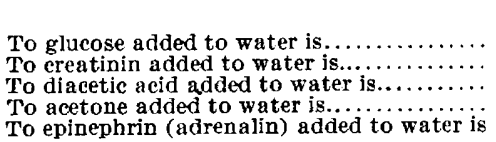 & $\begin{array}{l}\text { Gm. } \\
0.001 \\
0.00005 \\
0.00002 \\
0.00004\end{array}$ & $\begin{array}{l}\text { Added to blood } \\
\text { Added to blood } \\
\text { Added to blood } \\
\text { Added to blood } \\
\text { Added to blood }\end{array}$ & $\begin{array}{l}\text { Gm. } \\
0.0005 \\
0.00012 \\
0.00001 \\
0.000001 \\
0.0000005\end{array}$ \\
\hline
\end{tabular}

TABle 21.-The Picrate Sensitivity in Bloọ

To creatinin is approximately $\ldots \ldots \ldots \ldots \ldots, \quad 4$ times greater than to glucose
To diacetic acid is approximately $\ldots \ldots \ldots \ldots, 50$ times greater than to glucose
To acetone is approximately $\ldots \ldots \ldots \ldots \ldots, 500$ times greater than to glucose
To epinephrin (adrenalin) is approximately 1000 times greater than to glucose


In these experiments the aceto-acetic-ester is hydrolyzed to diacetic acid and ethyl alcohol in the process of the test. The diacetic acid is unstable and rapidly decomposes into acetone and carbon dioxid. Ethyl alcohol also influences the picrate solution. We are safe in making the statement that diacetic acid interferes when $0.25 \mathrm{mg}$. is added to 100 c.c. of blood or when $0.00002 \mathrm{gm}$. is added to a 2 c.c. sample of blood.

\section{DISCUSSION}

We have presented a series of experiments which tend to show that blood contains substances other than sugar which induce a color change in the picrate solution employed in the modified Lewis-Benedict blood sugar method. Under normal conditions, these substances may not interfere with the established normal range for this method. Under pathologic conditions several of these substances may interfere. Those which show the most marked influence are: epinephrin, acetone and diacetic acid. Creatinin may interfere, but does so in a less marked degree if we consider the comparative sensitiveness of the picrate solution to these substances.

As picrate solution reacts to smaller quantities of acetone than are normally present in the blood, the question may well be raised: do not the acetone bodies of the blood contribute to the established normal blood sugar range for the Lewis-Benedict test? Still another question may be asked: as epinephrin in infinitesimally small quantities induce a color change in the picrate solution, is it not possible that this substance when thrown into the general circulation, as is supposed to happen in emotional states, may induce a so-called hyperglycemia without mobilizing the glycogen stores of the liver? 